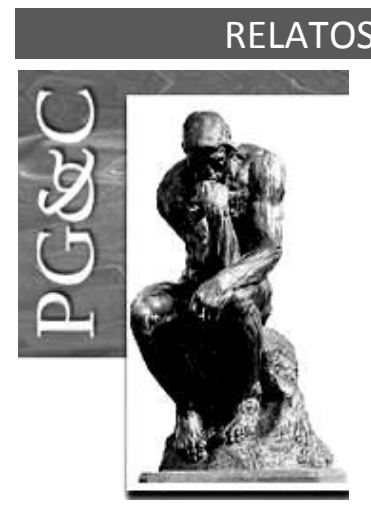

\title{
O COMPARTILHAMENTO DO CONHECIMENTO NA CADEIA PRODUTIVA DOS PEQUENOS FRUTOS
}

\author{
Roberta Rodrigues Faoro \\ Doutora em Administração pela Associação Pontifícia Universidade \\ Católica do Rio Grande do Sul/ Universidade de Caxias do Sul, Brasil. \\ Professora da Universidade de Caxias do Sul, Brasil. \\ E-mail: roberta.faoro@ucs.br \\ Chariel Simioni de Oliveira \\ Bacharela em Sistemas de Informação pela \\ Universidade de Caxias do Sul, Brasil. \\ E-mail: csoliveira3@ucs.br \\ Marcelo Faoro de Abreu \\ Doutor em Administração pela Universidade Federal do Rio Grande do \\ Sul, Brasil. Professor da Universidade de Caxias do Sul, Brasil. \\ E-mail: marcelo.faoro@ucs.br
}

\section{Resumo}

Este artigo tem como objetivo analisar como acontece o compartilhamento do conhecimento na cadeia produtiva dos pequenos frutos na região dos Campos de Cima da Serra. Foi realizada uma pesquisa qualitativa com os integrantes da cadeia produtiva, totalizando 12 entrevistados entre eles fornecedores de insumos, produtores, agroindústria, comércio no atacado, comércio varejista e consumidores. Pôde-se observar que o conhecimento nesse ambiente encontra-se na sua maior parte de forma tácita e que a maioria do compartilhamento existente ocorre de forma informal. Observa-se também que algumas empresas de maior porte já possuem o compartilhamento do conhecimento fazendo parte da sua cultura e reconhecem os benefícios trazidos por essa prática. Todos os entrevistados salientam a importância de compartilhar conhecimentos, porém são poucos que tem a iniciativa de promover essa atividade. Notou-se a resistência devido à competitividade quando se trata do compartilhamento entre empresas do mesmo setor. Por fim, foi possível perceber que as empresas reconhecem a importância do conhecimento e de seu compartilhamento, mas ainda se encontram dificuldades nesta prática.

Palavras-chave: Compartilhamento do Conhecimento. Cadeia Produtiva. Pequenos Frutos.

\section{SHARING KNOWLEDGE IN THE PRODUCTION CHAIN OF SMALL FRUITS}

\begin{abstract}
This article has the object of analyze how knowledge sharing happens inside the productive chain of small fruits in Campos de Cima da Serra region. A qualitative research was conducted with all members of the productive chain, totalizing thirteen interviewed including input suppliers, producers, agroindustry, wholesale trade, retail trade and consumers. The knowledge inside this environment can be observed that at the most time it is found as tacit form and the majority of existing sharing happens informally. It is also observed that some larger companies already have this sharing being part of your culture and they recognize the benefits brought by this practice. All the interviewed emphasize the importance of sharing knowledge, however, few of then have the initiative to promote such activity. It is noted the resistance due the competitiveness when it comes to sharing between companies of the
\end{abstract}


same sector. Lastly, it was possible to perceive that the companies recognize the importance of knowledge and the sharing of it, but they still find certain difficulties in this practice.

Keywords: Knowledge Sharing. Supply Chain. Small Fruits.

\section{INTRODUÇÃO}

O agronegócio vem cada vez sendo mais importante para o desenvolvimento do país, porém, ainda há a dificuldade de obter um conceito concreto e unânime. De acordo com Fernandes (2005) o conceito de agronegócio surgiu nos anos 80 e é um espaço que pode ser ocupado para o avanço do país com tecnologia e sustentabilidade. Já para Rufino (1999), o agronegócio se refere a produtos rurais produzidos com alta tecnologia que se utilizam das técnicas de produção intensiva, e o uso de fertilizantes aumentando notavelmente a produtividade.

O Brasil é um dos líderes mundiais do agronegócio. Setor de suma importância para a economia do país. O agronegócio gera grande participação no PIB - Produto Interno Bruto, no ano de 2015 foi responsável por $21,46 \%$ (CEPEA, 2016), além de gerar $37 \%$ do número total de empregos do país (OLIVEIRA, 2015). Entre junho de 2014 e maio de 2015, as exportações do agronegócio brasileiro alcançaram a quantia de US\$ 91,38 bilhões isso representa que 51,5\% das exportações brasileiras foram provenientes do agronegócio (GLOBO, 2015).

O Rio Grande do Sul está entre os estados mais competitivos do agronegócio segundo pesquisa realizada pela Confederação Nacional da Agricultura ficando em segundo lugar (GLOBO, 2015). Sendo que na região dos Campos de Cima da Serra - RS, o agronegócio é considerado a principal atividade econômica, fechou o ano de 2012 com um PIB per capita de $\mathrm{R} \$ 23.618$ (COREDES, 2015). Esta região é responsável por aproximadamente $75 \%$ da produção nacional de pequenos frutos como amora, mirtilo, framboesa, physalis e o morango. Também é referência na produção de maçã e mel (OTOBELLI, 2013).

Atualmente, é exigido um diferencial para manter-se estável no mercado, aplicação de tecnologias, estruturação e adequado aproveitamento do conhecimento, ou seja, o intangível é valorizado, é necessário ser visto e trabalhado. Lev diz que (2000, p. 34) "os ativos intangíveis estão rapidamente se tornando substitutos dos ativos físicos".

Neste sentido, Tonet e Paz (2006, p. 2) definem que "o comportamento do indivíduo de repassar o que sabe às pessoas com quem trabalha e de receber o conhecimento que elas possuem é compartilhar conhecimento". Complementando Grotto (2003, p. 116) diz que o "compartilhamento do conhecimento é o processo de partilhar conhecimentos tácitos e explícitos por meio de práticas formais e informais". Já Davenport (1998, p. 114) entende o compartilhamento do conhecimento como "o ato voluntário de colocá-las [informações e/ou conhecimentos + à disposição de outros]" conforme o autor o ato de compartilhar o conhecimento se distingue de relatos. Relatar é uma troca involuntária de informações rotineiramente, já compartilhar o conhecimento demanda vontade, as pessoas que compartilham passam a informação adiante, mas não são obrigados a isso (DAVENPORT, 1998).

Assim sendo, o compartilhamento do conhecimento está ganhando maior destaque nas organizações. Nos últimos dez anos muito tem sido pesquisado e desenvolvido a respeito do assunto. No quadro econômico político e social que estamos onde a globalização e a concorrência são pujantes os componentes da cadeia produtiva do agronegócio devem manter um olhar atento sobre os "ativos intangíveis" (STEWART, 1998). Dito de outra forma, o compartilhamento do conhecimento entre os integrantes da cadeia produtiva do agronegócio pode auxiliar na potencialização da produtividade além de obter maiores informações sobre

Perspectivas em Gestão \& Conhecimento, João Pessoa, v. 8, n. 2, p. 82-106, mai./ago. 2018. 
novidades da área, novas técnicas, novos materiais, notícias e dicas para resolução de problemas.

Deste modo, a região dos Campos de Cima da Serra/RS é integrante fundamental do agronegócio brasileiro. Para que haja uma melhora no desenvolvimento deste setor é importante que os membros que integram a cadeia interajam entre si. Podendo assim trocar experiências e conhecimentos da área de interesse, agregando valor à cadeia em que pertencem. Diante disso, o presente estudo tem como objetivo principal analisar como acontece o compartilhamento do conhecimento na cadeia produtiva dos pequenos frutos na região dos Campos de Cima da Serra do Estado do Rio Grande do Sul.

Este artigo está estruturado da seguinte forma: na seção 2, a revisão da literatura sobre compartilhamento do conhecimento, agronegócio e cadeia produtiva. Na seção 3, os procedimentos metodológicos adotados são abordados. Na seção 4, o estudo de caso é apresentado e na seção 5 , os dados são analisados e os resultados são discutidos à luz da teoria. Por fim, na seção 6 , as conclusões são apresentadas.

\section{REFERENCIAL TEÓRICO}

Este estudo aborda o compartilhamento do conhecimento na cadeia produtiva dos pequenos frutos. Na seção 2.1 discutem-se os conceitos sobre o agronegócio e o seu papel na economia brasileira. Na seção 2.2 é abordada a cadeia produtiva. Já a seção 2.3 refere-se ao conhecimento e por fim na seção 2.4 o compartilhamento do conhecimento.

\subsection{Agronegócio}

O Agronegócio teve sua definição brasileira criada em meados da década de 80 , e foi definido como sendo pensamentos que visam à transformação do sistema latifundiário da agricultura capitalista. Entre os diversos autores que estudaram o agronegócio podemos destacar Davis e Goldberg (1957), Rufino (1999), Zylbersztajn (2000), Fernandes (2005), Neves (2006) e Toresan (2006).

De acordo com Toresan (2006) e Zylbersztajn (2000), o primeiro significado de agronegócio veio de dois professores, economistas, da Universidade de Harvard, John H. Davis e Ray Goldberg. Eles viram que havia um sistema diferente do antigo, que seria o conjunto das operações de produção e distribuição de insumos e novas tecnologias agrícolas, da produção, do armazenamento, do transporte, do processamento e distribuição dos produtos agrícolas e seus derivados. Na visão de Davis e Goldberg, a agricultura não poderia ficar separada dos outros agentes responsáveis por todas as atividades até que o produto chegasse ao consumidor final, os professores acreditavam que cada atividade agrícola fazia parte de uma rede que ia desde a produção de insumos, transformação industrial até armazenagem e distribuição de produtos agrícolas e derivados. Deram o nome a este sistema de agribusiness (JAMANDRE, 2015).

Davis e Goldberg (1957, p. 1) definem o agribusiness como "a soma total das operações de produção e distribuição de suprimentos agrícolas; das operações de produção na fazenda; do armazenamento, processamento e distribuição dos produtos agrícolas e itens produzidos a partir deles".

De acordo com o Ministério da Agricultura, Pecuária e Abastecimento - MAPA (2015) no ano de 2014 o agronegócio foi responsável por 1,8 trilhões do Produto Interno Bruto o que representa $24 \%$. No mesmo ano exportou US\$ 96,8 bilhões, ou seja, $43 \%$ das exportações foram advindas do agronegócio.

Perspectivas em Gestão \& Conhecimento, João Pessoa, v. 8, n. 2, p. 82-106, mai./ago. 2018. 


\title{
2.1.1 Agronegócio no Brasil
}

A primeira atividade econômica do Brasil foi à extração do pau-brasil. Logo veio a extinção do pau-brasil foi então que se deu início na plantação da lavoura canavieira, que foi de grande importância para a economia. A produção foi iniciada no decorrer do século XVI por meio de doações de terras incultas para inicio do plantio, a plantação de cana-de-açúcar com regime escravocrata foi responsável pela expansão do latifúndio. Em terras onde as condições ambientais não colaboravam para a produção da cana foram criados bois para corte e para tração. Com o desenvolvimento destas duas culturas até o século XVIII, foi estabelecida uma agricultura de subsistência que garantia o sustento de pessoas que colaboravam nos engenhos e fazendas de gado. A partir de então a mineração sob a forma de garimpos tornou-se a principal atividade do país. Foi então que a os produtos da agricultura passam a ser comercializados. No século XIX, foi expandido o território de ocupação brasileiro, resultando no aumento das propriedades. No século XX, predominou o cultivo do café e da cana-deaçúcar (LIMA; LOURENÇO, 2009).

\begin{abstract}
Em síntese, fica evidente que, a partir da década de 1930, com maior intensidade na de 1960 até a de 1980, o produtor rural passou, gradativamente, a ser um especialista, envolvido quase exclusivamente com as operações de cultivo e criação de animais; por sua vez, as funções de armazenar, processar e distribuir produtos agropecuários, bem como as de suprir insumos e fatores de produção, foram transferidas para organizações produtivas e de serviços nacionais e/ou internacionais fora da fazenda, impulsionando, com isso, ainda mais a indústria de base agrícola (MONTOYA, 2002 p. 1).
\end{abstract}

De acordo com Vieira (2000), o agronegócio é uma opção de desenvolvimento econômico para o agricultor, criando oportunidades para obter uma melhor qualidade de vida na zona rural do RS, através da produção agrícola.

Segundo pesquisa do MAPA (2015) o Valor Bruto da Produção da agricultura e da pecuária do estado somou $\mathrm{R} \$ 48,5$ bilhões em 2014. A produção pecuária totaliza $R \$ 15,8$ bilhões (32,6\%), e a agricultura, R\$ 32,7 bilhões (67,4\%). Em 2014 as exportações do Estado tiveram como destino 198 países, sendo a China o principal comprador. Em seguida, aparecem Estados Unidos, Países Baixos, Coréia do Sul, Rússia e Venezuela. Totalizando US\$ 12,2 bilhões, o que equivale a $65 \%$ do total de importações do Estado no referido ano. Os principais complexos exportadores do agronegócio são os da soja, de carnes, de fumo e de couros, além de uma parcela expressiva da produção agropecuária ser exportada na como matéria-prima ou alimentos processados.

\subsection{Cadeia Produtiva}

Montigaud (1991) diz que uma cadeia de produção é um aglomerado de atividades de produção e distribuição ligadas entre si e relacionadas verticalmente, por pertencerem a um mesmo ou semelhante produto.

Uma sucessão de operações de transformação dissociáveis, capazes de ser separadas e ligadas por um encadeamento técnica [...] e também um conjunto de relações comerciais e financeiras, que estabelecem, entre os estados de transformação, um fluxo de troca, situado a montante e a jusante, entre fornecedores e clientes (Batalha, 1997, p. 24).

Perspectivas em Gestão \& Conhecimento, João Pessoa, v. 8, n. 2, p. 82-106, mai./ago. 2018. 

maneiras:

De acordo com Morvan (1991), cadeia de produção pode ser abordada de três

1. Como uma sucessão de operações de transformação de matérias-primas em produtos finais, capazes de ser separadas e ligadas entre si por um encadeamento técnico;

2. Como um conjunto de relações comerciais entre fornecedores e clientes; e

3. Como um conjunto de ações econômicas que presidem a valoração dos meios de produção.

Para melhor entender o conceito de cadeia produtiva Durski pontua:

Uma simples empresa geralmente não esta habilitada a controlar seu fluxo de produtos inteiro no canal, desde as fontes da matéria-prima até o ponto final de consumo, embora estas sejam uma oportunidade emergente. Cadeia produtiva é o conjunto de atividades econômicas que se articulam progressivamente desde o inicio da elaboração de um produto (DURSKI, 2003, p. 29).

A Figura 1 apresenta um modelo geral de uma cadeia produtiva, com os seus principais componentes e fluxos. São diferenciados os componentes mais comuns, ou seja, o mercado consumidor, a rede de atacadistas e varejistas, a indústria de processamento, as propriedades agrícolas, com seus diversos sistemas produtivos agropecuários ou agroflorestais e os fornecedores de insumos. Esses componentes estão relacionados a um ambiente institucional e a um ambiente organizacional que em conjunto, exercem influência sobre os componentes da cadeia e sobre o seu desempenho como um todo.

Figura 1 - Modelo geral da cadeia produtiva

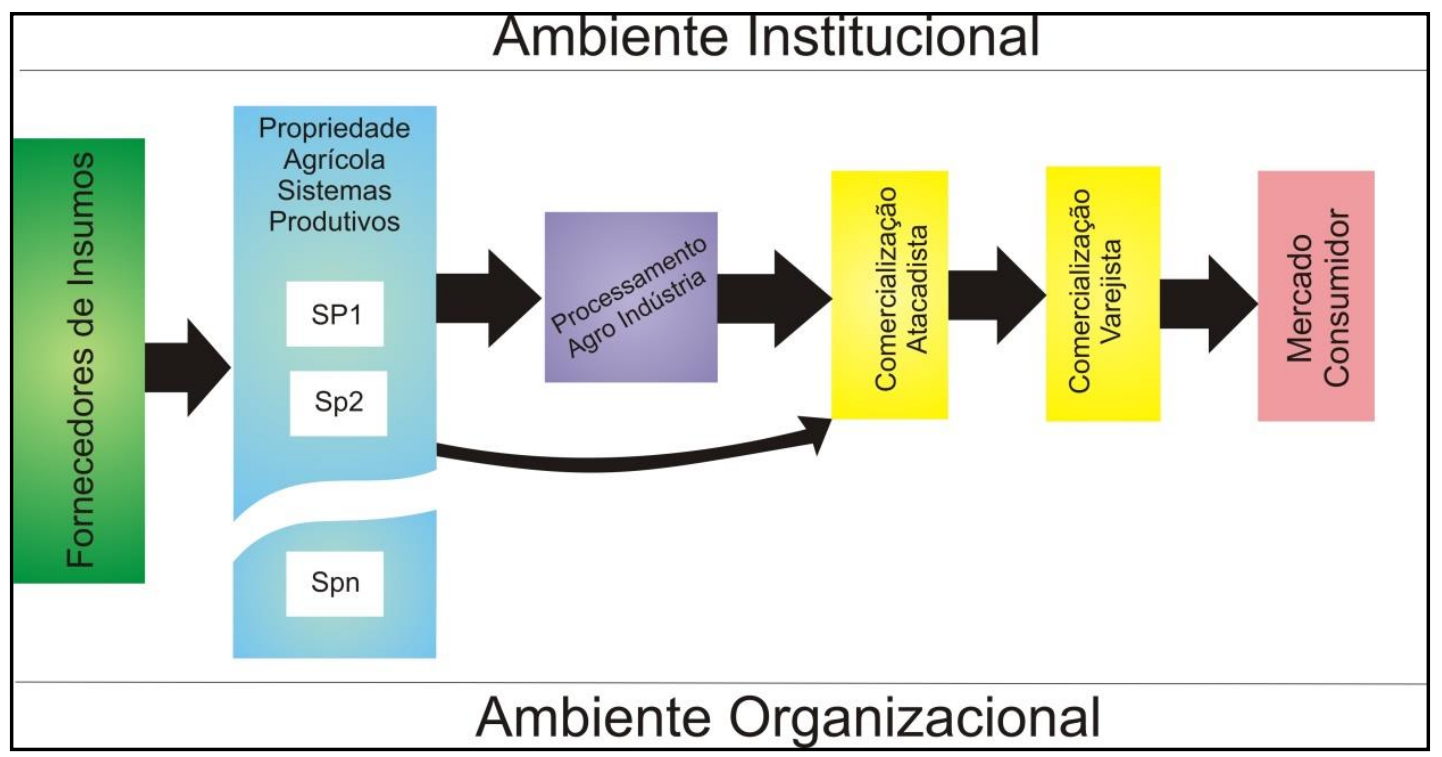

Fonte: Adaptado de Zylberstajn (1994, p. 30)

As cadeias produtivas devem sanar as necessidades do consumidor final por meio de produtos de qualidade e quantidade compatíveis e a preços competitivos. Por este motivo, a influência do consumidor final é muito forte sobre os demais elos que fazem parte da cadeia por isso é de grande valia conhecer as demandas desse mercado consumidor (CASTRO, 2001).

De acordo com os estudos dos autores Dantas, Kertsntzky e Prochnnik (2002, p. 120), "pode-se obter cadeias mais ou menos agregadas, dependendo da variação da amplitude do 
leque de produtos considerados, como é o caso dos complexos industriais". Segundo os autores a cadeia produtiva é mais abrangente tendo outras formas de cadeias.

Considerando-se longitudinalmente, pode-se ter uma cadeia produtiva empresarial onde cada etapa representa uma empresa, cujo desenho é encontrado, por exemplo, em supply chain management. Em um nível mais agregado, encontrando-se as cadeias produtivas setoriais, nas quais as etapas são setores econômicos e os intervalos são os mercados entre setores consecutivos (DANTAS; KERTSNTZKY; PROCHNNIK, 2002, p. 120).

Na visão de Cristopher (1997) é normal que as cadeias unam seus elos, estabelecendo uma relação com todos os autores do inicio ao fim da cadeia, porém não conseguem analisar como um conjunto e esse relacionamento é visto como uma competição entre ambos se veem isoladamente e não em uma cadeia.

\subsubsection{Cadeia Produtiva dos Pequenos Frutos}

Para Pagot (2007) "a cadeia de produção de Pequenas Frutas possui uma importância social econômica significativa, rendendo inclusive divisas através da comercialização e da exportação".

A região dos Campos de Cima da Serra é conhecida por ser a maior produtora brasileira de pequenas frutas. Existem diversas nomenclaturas para esses frutos como: frutos silvestres, small fruits ou ainda frutas vermelhas. Devido os cuidados necessários e a rentabilidade das plantações, a cultura se torna alternativa ideal para os minifúndios em que a agricultura familiar é à base da produção (ANTUNES, 2007).

As pequenas frutas compreendem uma série de espécies como a amora-preta, a framboesa, o morango, o mirtilo, e o physalis elas têm despertado a atenção e o interesse por parte de produtores, comerciantes e consumidores. Elas apresentam grande importância social e econômica na região dos Campos de Cima da Serra do Rio Grande do Sul com destaque nos municípios de Vacaria, Campestre da Serra e Ipê, onde se estima que cerca de 400 famílias trabalhem diretamente nas cadeias produtivas desses alimentos (PAGOT; HOFFMANN, 2003).

O cultivo destes frutos é caracterizado pelo baixo custo de implantação, custo de produção acessível, bom retorno econômico, boa adaptação às condições socioeconômicas e do ambiente local, grande exigência de mão-de-obra, possibilidade de cultivo no sistema orgânico e demanda maior do que a oferta (POLTRONIERI, 2003).

A produção de pequenas frutas pode significar muito para 0 desenvolvimento da região, colaborando para o fortalecimento da agricultura familiar, gerando empregos e renda através do aumento da produção e processamento dessa matéria prima (ALARCAN, 2003, p. 15).

Conforme Ormond et al. (2002) para ser possível um melhor entendimento a respeito de uma cadeia produtiva, é preciso conhecer os elos e relacionamentos entre os atores envolvidos e identificar os pontos fortes e fracos da cadeia.

Na Figura 1, pode-se perceber uma divisão da cadeia da produtiva em quatro grandes setores: insumos, produção, indústria e comércio. O setor de insumos envolve máquinas, equipamentos, ferramentas agrícolas, ofensivos agrícolas, adubos, fertilizantes, substratos, mudas, sementes, equipamentos de irrigação e embalagens. Diretamente ligada a este setor temos a Produção a qual envolve produtores integrados, pequenos e médios produtores, cooperativas e associações, produção verticalização, cultivo de pequenos frutos, cultivo de 
lavoura permanente e temporária. Após a produção segue-se para o setor destinado a Indústria ou Transformação, que possui intermédio dos Packing Houses, os quais mantêm relação com frutas frescas ou a indústria de alimentos e bebidas. A segunda opção refere-se ao processamento e produção de conservas, doces e lácteos, assim como, frutas minimamente processadas, produção de suco, polpas e bebidas prontas como néctar e refresco. As frutas frescas e a indústria de alimentos e bebidas conectam-se aos atacadistas e cooperativistas exportadoras, pois já se encontram prontas para o comércio. Os intermediários Packing Houses que fazem parte do setor da indústria também são ligados diretamente ao mercado atacadista (centros de abastecimentos) e/ou ao mercado varejista (sacolões, feiras livres, supermercados, cozinhas industriais) ambos os mercados ligam-se entre si para então chegar ao consumidor final e encerrar a cadeia produtiva. Por fim, em torno de todos estes elos, ainda interage uma intensa rede de formadores dos ambientes organizacionais (BIZOTTO, 2011).

\subsection{Conhecimento e Conversão do Conhecimento}

"Conhecimento é uma mistura fluida de experiências condensada, valores, informação contextual e insight experimentado, a qual proporciona uma estrutura para a avaliação e incorporação de novas experiências e informações" (DAVENPORT; PRUSAK,1999, p. 6). Para os autores o conhecimento se desenvolve ao longo do tempo através da experiência e que abrange aquilo que observamos em cursos, livros e mentores e também no aprendizado informal.

Já Nonaka e Takeuchi (1995) definem o conhecimento como informação combinada com experiência, outros conhecimentos, crenças, as lições aprendidas e assimiladas por pessoas. Eles revelam que existem duas formas de conhecimento: o e explicito e o tácito (NONAKA; TAKEUCHI, 1997). No Quadro 1 pode-se observar as características de cada tipo de conhecimento.

Quadro1 - Tipos de Conhecimento

\begin{tabular}{|l|l|}
\hline Conhecimento Tácito (Subjetivo) & Conhecimento Explícito (Objetivo) \\
\hline Conhecimento da experiência (corpo) & Conhecimento da racionalidade (mente) \\
\hline Conhecimento simultâneo (aqui e agora) & Conhecimento sequencial (lá e então) \\
\hline Conhecimento análogo (prática) & Conhecimento digital (teoria) \\
\hline
\end{tabular}

Fonte: Adaptado de Nonaka e Takeuchi (1997, p. 67)

Para Brito et al. (2012), o conhecimento explícito é fácil transmitir e é registrado, já o conhecimento tácito é subjetivo com isso se torna difícil de ser gerenciado dentro das organizações. Segundo Nonaka e Von Krogh (2009) o conhecimento explicito é universal e pode atuar em diversos contextos, pode ser verbalizado e documentado é o conhecimento que pode ser transmitido para outras pessoas, formal e sistêmico.

Em contrapartida o conhecimento tácito é de difícil extração e manipulação, é internalizado pelo individuo que o possui, refere-se à prática adquirida pela experiência. Em linguagem popular é o que o individuo aprendeu fazendo (NONAKA, 1994; NONAKA; TAKEUCHI, 1995).

De acordo com Nan (2008), o conhecimento tácito pode ser dividido em dois: conhecimento expresso (conjunto de regras ou passo a passo para que outra pessoa consiga exercer a tarefa ou obter o conhecimento da mesma maneira) e conhecimento inexprimível (não consegue ser transmitido, apenas o individuo que o possui consegue exercer). 0 conhecimento é criado por meio da interação do conhecimento tácito e do explícito. Essa interação é chamada de conversão do conhecimento (NONAKA; TAKEUCHI, 1997).

Perspectivas em Gestão \& Conhecimento, João Pessoa, v. 8, n. 2, p. 82-106, mai./ago. 2018. 
De acordo com Nonaka e Takeuchi (2008), existem quatro modos de conversão do conhecimento que são:

- Socialização: é compartilhar e criar conhecimento tácito através de experiências diretas. É uma maneira de criar conhecimento que visa à conversão do conhecimento tácito por meio da interação entre indivíduos. É relevante citar que um indivíduo pode adquirir conhecimento tácito sem usar a linguagem, mas pela observação, prática e imitação, ou seja, a chave para a aquisição de conhecimento tácito é a experiência (NONAKA, 1994, NONAKA; TAKEUCHI, 1995).

- Externalização: é articular conhecimento tácito através do diálogo e da reflexão. É um modo de criação de conhecimento o qual busca a conversão do conhecimento tácito em conhecimento explícito. Pode ser expresso na forma de metáforas, analogias, conceitos, hipóteses ou modelos. Dentre os quatro modos de conversão do conhecimento, a externalização cria novos conceitos a partir do conhecimento tácito (NONAKA; TAKEUCHI, 1995).

- Combinação: é sistematizar e aplicar o conhecimento explícito e a informação. É um modo de criação de conhecimento que envolve o uso de processos sociais para combinar diferentes tipos de conhecimento explícito dos indivíduos. Os indivíduos trocam e combinam conhecimentos através de mecanismos, como reuniões e conversas telefônicas. A reorganização assim como a recontextualização do conhecimento explícito pode levar a novos conhecimentos (NONAKA, 1994, NONAKA; TAKEUCHI, 1995).

- Internalização: é aprender e adquirir novo conhecimento tácito na prática. É um modo de criação de conhecimento que permite unir o conhecimento explícito no conhecimento tácito. É aprender com a prática. Quando são internalizadas nas bases do conhecimento tácito dos indivíduos sob a forma de modelos mentais ou experiências compartilhadas através da socialização, externalização e combinação tornam-se ativos valiosos (NONAKA; TAKEUCHI, 1995).

Segundo Nonaka e Takeuchi (1997), a criação do conhecimento baseia-se nesta conversão, pois é por meio dela são criados os conceitos explícitos com base em conhecimento tácito. Ainda, os autores ressaltam que a conversão do conhecimento não acontece de forma, reta ou paralela e sim ocorre em forma de espiral, conforme ilustrado na Figura 2.

Figura 2 - Espiral do Conhecimento

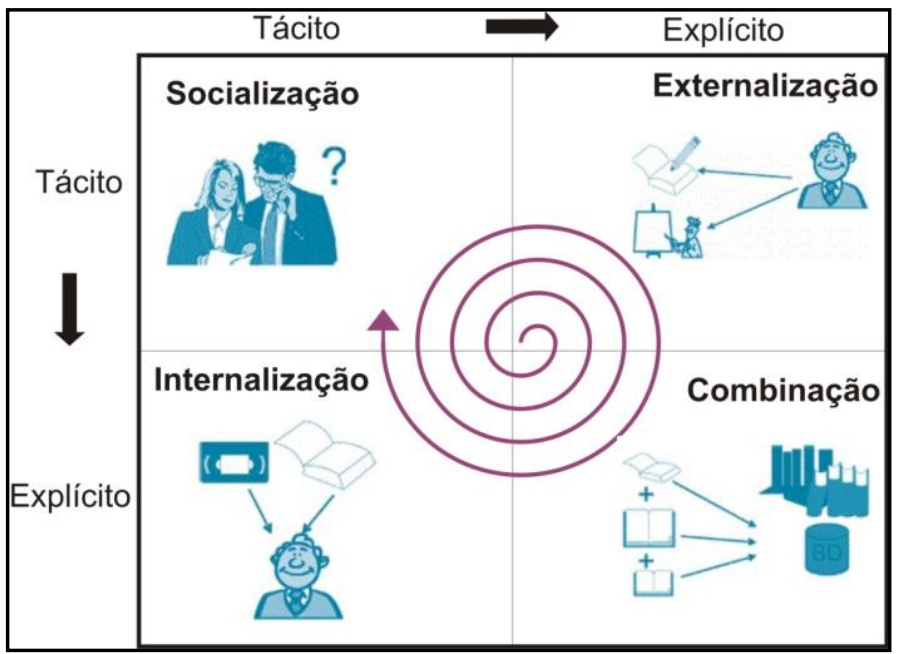

Fonte: Adaptado de Nonaka; Takeuchi (1997) 
A Espiral do Conhecimento é formada pelos modos de conversão do conhecimento. $\mathrm{Na}$ socialização ocorre a criação e compartilhamento do conhecimento tácito através da interação entre as pessoas, sendo que existe a conversão do conhecimento tácito para o tácito. $\mathrm{Na}$ externalização ocorre a conversão do conhecimento tácito em explícito, sendo que o conhecimento individual passa a ser compartilhado por um grupo. Na combinação ocorre a sistematização do conhecimento explícito, onde o conhecimento explícito se transforma em explícito, passando do grupo para a organização. Na internalização ocorre a conversão do conhecimento explícito em tácito, onde o conhecimento passa da organização para 0 indivíduo. (TAKEUCHI; NONAKA, 2008).

Stewart (1998) enfatiza que o conhecimento tornou-se o principal ingrediente do que produzimos fazemos compramos e vendemos. É importante perceber que o conhecimento não é sinônimo de acúmulo de informações, o termo "conhecimento" significa compreender todas as dimensões da realidade, captando e expressando essa totalidade de forma cada vez mais ampla e integral (ANGELONI, 2002).

\subsection{Compartilhamento do Conhecimento}

Lee (2001) define o compartilhamento de conhecimento como atividades de transferência ou disseminação do conhecimento a partir de uma pessoa, grupo ou organização para outra. Já para Christensen (2007), o compartilhamento do conhecimento é uma forma de resolução de problemas ou tarefas de forma rápida, econômica e certeira, por meio de experiências de outros. Com isso, "o objetivo do compartilhamento do conhecimento pode ser a criação de novos conhecimentos de forma diferente para combinar o conhecimento existente ou para tornar-se melhor em explorar o conhecimento existente" (CHRISTENSEN, 2007, p. 37).

Li $(2010$, p. 40) aponta que "o compartilhamento do conhecimento é um processo coletivo por natureza, porque os participantes precisam estar envolvidos no processo, se eles realmente querem compartilhar conhecimento". Para Faoro e Oliveira (2014, p. 114) "o compartilhamento do conhecimento pode auxiliar as empresas, independente do porte, pois visa difundir o know-how obtido pelas experiências dos colaboradores e parceiros ao longo do tempo". Ainda assim, Oliveira e Sauer (2016, p. 175) em seu estudo, apresentam "que houve o florescimento de ideias, planos e proposições produzidos pelos próprios integrantes da organização, graças ao contexto compartilhado de conhecimento que possibilitou a manifestação de seus traços culturais, antes não disseminados".

O Compartilhamento do Conhecimento pode acontecer de duas formas: intraorganizacional (conhecimento interno, a organização é o centro das informações onde o doador e o receptor ali estão, ou seja, o conhecimento não sai dali, fica somente sendo compartilhando dentro da organização) e interorganizacional (conhecimento externo, onde o conhecimento ultrapassa a porta da organização, ou seja, as organizações da mesma linha trocam conhecimento entre si). (JARVENPAA; STAPLES, 2001). Porém, de acordo com Lee (2001), compartilhar o conhecimento entre diferentes organizações não é fácil. Tsai (2002) aponta que, o compartilhamento do conhecimento flui melhor em ambientes informais em ambientes que as relações sociais acontecem naturalmente entre as organizações.

Na visão de Cheng, Yeh e Tu (2008) a confiança é a base para que o compartilhamento do conhecimento aconteça e cada vez se solidifique mais entre as partes. Uma vez que, quanto mais um fator contribui para a confiança positivamente (como a participação e comunicação) ou negativamente (como comportamento oportunista), faz com que o compartilhamento de conhecimento seja retribuído por ambas às partes.

Neste sentido, o estudo de Sordi, Binotto e Ruviaro (2014) mostrou a confiança entre os indivíduos como um fator influente no compartilhamento de conhecimentos entre os

Perspectivas em Gestão \& Conhecimento, João Pessoa, v. 8, n. 2, p. 82-106, mai./ago. 2018. 
mesmos. Ainda, para os autores, o nível de competição existente em um determinado grupo de indivíduos influencia no grau de compartilhamento de conhecimentos entre os mesmos.

De acordo com Wang e Noe (2010), mesmo com todo o material teórico já publicado sobre o assunto, ainda há a necessidade de se investigar e compreender melhor sobre o tema. Para isso, buscando a contemplação dos objetivos do estudo, a próxima seção vai abordar sobre o compartilhamento de conhecimento na cadeia produtiva dos pequenos frutos, no sentido de ampliar o arcabouço teórico existente.

\subsubsection{Compartilhamento do Conhecimento na Cadeia Produtiva dos Pequenos Frutos}

O conhecimento tornou-se uma ferramenta para o progresso das organizações. As mudanças econômicas, tecnológicas, políticas e sociais, resultaram em uma modificação dos valores da sociedade, onde o conhecimento passou a ser fundamental em todas as atividades econômicas sendo considerado um recurso estratégico para as empresas (ANGHINONI, 2005).

Anghinoni (2005, p. 3) enfatiza que "diante desta realidade de transformações constantes e rápidas, o conhecimento torna-se fator importante no cenário do agronegócio". Desta maneira, as empresas do agronegócio precisam tratar o conhecimento como base primordial para planejar e agir.

As empresas do agronegócio têm problemas para identificar e guardar os ativos do conhecimento. A identificação de quem são esses ativos é fundamental para o crescimento e desenvolvimento de negócios não só do ramo do agronegócio como para todos os ramos. Essa identificação poderá se transformar na principal fonte de vantagem competitiva (ANGHINONI, 2005).

Neste sentido, o estudo de Faoro e Oliveira (2014) observou que nas empresas do setor de fruticulturas, existem compartilhamento de conhecimento interno e externo, porém totalmente informal, que ocorre dentro das rotinas operacionais diárias e que não há uma preocupação explícita com tal assunto por parte dos gestores das mesmas. Verificou-se ainda, que existe um terreno fértil para a organização dos processos de compartilhamento de conhecimento, com vistas à obtenção de eficiências e vantagens competitivas

Além disso, Dyer e Nobeoka (2000) entendem que a capacidade de aprendizagem de uma organização não se resume apenas em si própria, isolada, necessita para isso a análise da cadeia na qual está inserida. A organização deve fazer parte ativamente da cadeia a qual faz parte se tornando um elemento aglutinador devido à criação de atividade para exercer o compartilhamento de conhecimento entre os membros participantes. A produção de conhecimento é vista como resultado da cadeia e, portanto, compartilhada por todos os membros que a integram. Assim, a cadeia como um todo tem acesso a conhecimentos variados, com um custo muito menor do que se buscassem o conhecimento sozinha.

Anghinoni (2005) diz que as cadeias constituem capacidades que aumentam o valor das empresas. Elas precisam ser entendidas como sendo fluxos de conhecimento que atravessam as empresas e que o compartilhamento do conhecimento aumenta a capacidade de inovação das empresas participantes.

Sendo assim, com o objetivo de promover o desenvolvimento e difundir o conhecimento a respeito do sistema de produção de pequenas frutas no Brasil, é realizado periodicamente seminários e feiras. Onde é disponibilizada capacitação, intercâmbio e difusão de informações, discussão e atualização técnica sobre os sistemas de produção de morangos, amora-preta, framboesa e physalis, além de palestras e painéis sobre mercado e logística, póscolheita e processamento de pequenas frutas. Palestrantes brasileiros e de outros países produtores, como a Argentina e Uruguai fazem parte dos seminários, agregando valor ao evento. Devido à espécie frutífera ainda não ter se difundido é importante à discussão e o intercâmbio de informações contribuindo para a viabilização do cultivo destas espécies no Brasil (EMBRAPA, 2015).

Perspectivas em Gestão \& Conhecimento, João Pessoa, v. 8, n. 2, p. 82-106, mai./ago. 2018. 


\title{
3 MÉTODO DE PESQUISA
}

O presente trabalho foi desenvolvido a partir de uma pesquisa de natureza básica abordando o problema de forma qualitativa, a qual não leva em consideração números, mas sim a melhor compreensão de um grupo ou situação (GOLDENBERG, 1999). Para Minayo (2001, p.14) a pesquisa de caráter qualitativo:

trabalha com o universo de significados, motivos, aspirações, crenças, valores e atitudes, o que corresponde a um espaço mais profundo das relações, dos processos e nos fenômenos que não podem ser reduzidos a operacionalização de variáveis (MINAYO, 2001, p.14).

Do ponto de vista de seus objetivos é exploratória, "a pesquisa exploratória tem por objetivo proporcionar maior familiaridade com o problema, esclarecer e modificar conceitos e ideias tendo em vista, a formulação de problemas mais precisos" (GIL, 2002, p. 43).

Foi elaborado um protocolo preliminar (DUBÉ; PARÉ, 2003), que foi submetido a um especialista da área de gestão de TI e outro da área da Agronomia, a fim de detectar eventuais inconsistências, redundâncias ou outros problemas. A partir do retorno das sugestões feitas pelos especialistas o instrumento foi revisado.

A estratégia utilizada na pesquisa foi o estudo de caso sobre a cadeia produtiva dos pequenos frutos, localizada nos Campos de Cima da Serra no Estado do Rio Grande do Sul. Para Fonseca (2002, p. 33), um estudo de caso pode ser caracterizado como:

\begin{abstract}
um estudo de uma entidade bem definida como um programa, uma instituição, um sistema educativo, uma pessoa, ou uma unidade social. Visa conhecer em profundidade o como e o porquê de uma determinada situação que se supõe ser única em muitos aspectos, procurando descobrir o que há nela de mais essencial e característico. O pesquisador não pretende intervir sobre o objeto a ser estudado, mas revelá-lo tal como ele o percebe. $\mathrm{O}$ estudo de caso pode decorrer de acordo com uma perspectiva interpretativa, que procura compreender como é o mundo do ponto de vista dos participantes, ou uma perspectiva pragmática, que visa simplesmente apresentar uma perspectiva global, tanto quanto possível completa e coerente, do objeto de estudo do ponto de vista do investigador (FONSECA, 2002, p. 33).
\end{abstract}

Foram aplicadas técnicas padronizadas de coleta de dados: entrevistas, análise de documentos, site e foi também feita observação direta. No olhar de Bauer e Gaskell (2000), com a entrevista é possível ter uma maior compreensão do assunto em questão além de obter informações importantes para o entendimento de alguns fatores específicos. As entrevistas foram feitas individualmente com os integrantes da cadeia produtiva do agronegócio, foram gravadas para posteriormente transcritas e analisadas.

Assim sendo, foram entrevistados três consumidores, três produtores, dois gestores de uma indústria, um gestor do comércio atacadista, e um comércio varejista e dois gestores da distribuidora de insumos, localizados na região dos Campos de Cima da Serra no estado do Rio Grande do Sul. $O$ total foram realizadas 12 entrevistas, com aproximadamente 30 minutos cada uma. Todas as entrevistas foram gravadas com a autorização dos entrevistados, e posteriormente foram transcritas na forma literal. O período das entrevistas foi de maio a junho de 2016 e o período de transcrição das entrevistas foi no mês de julho de 2016. 
A técnica mais pertinente quando o pesquisador quer obter informações a respeito do seu objeto, que permitam conhecer sobre atitudes, sentimentos e valores subjacentes ao comportamento, o que significa que se pode ir além das descrições das ações, incorporando novas fontes para a interpretação dos resultados pelos próprios entrevistadores (RIBEIRO, 2008, p.141).

Após a coleta dos dados foi feita a análise interpretação dos dados obtidos. Gil (1999, p. 168) diz que:

A análise tem como objetivo organizar e sumariar os dados de tal forma que possibilitem o fornecimento de respostas ao problema proposto para investigação. Já a interpretação tem como objetivo a procura do sentido mais amplo das respostas, o que é feito mediante sua ligação a outros conhecimentos anteriormente obtidos (GIL, 1999, p. 168).

Consoante Yin (2001) a análise dos dados é a atividade de examinar, categorizar, classificar, testar e recombinar evidências. Pensando nesta definição os dados coletados para o desenvolvimento desta pesquisa foram analisados com o auxilio do software MaxQda.

\section{ESTUDO SOBRE A CADEIA PRODUTIVA DOS PEQUENOS FRUTOS}

O estudo foi realizado sobre a cadeia produtiva dos pequenos frutos dos Campos de Cima da Serra do Estado do Rio Grande do Sul. Sendo três empresas de produção, uma distribuidora de insumos, uma empresa da agroindústria, uma empresa representando o comércio varejista e uma empresa do comércio atacadista. Além de três consumidores sendo um deles pessoa jurídica.

Como alguns gestores solicitaram que os nomes de suas empresas não fossem divulgados, optou-se por não divulgar o nome de nenhuma das empresas pesquisadas, mantendo assim a privacidade de cada uma delas. As empresas e pessoas que foram entrevistadas serão identificadas por um pseudônimo: Consumidor 1, Consumidor 2, Consumidor 3, Produtor 1, Produtor 2, Produtor 3, Indústria, Varejista, Atacadista, Insumos.

O Consumidor 1 é pessoa física, do sexo feminino, tem ensino médio completo é técnica em enfermagem, 26 anos e reside em Vacaria. O Consumidor 2 é pessoa física, do sexo feminino, tem ensino médio completo é técnica em enfermagem, 57 anos e reside em Vacaria. O Consumidor 3 é pessoa jurídica, classificada como microempresa. Atua no ramo alimentício há dois anos, com a produção e comercialização de lanches e bebidas. Eles possuem estrutura própria localizada na cidade de Vacaria.

O Produtor 1, é pessoa jurídica do ramo da fruticultura, trabalha com a produção e também compra de pequenas frutas. Está há 15 anos no mercado, classificada como empresa de médio porte. Já foi considerado um dos maiores produtores brasileiros de morango. Conta com 150 colaboradores fixos e 40 temporários. O Produtor 2, é pessoa jurídica do ramo da fruticultura, trabalha com a produção, compra e venda de pequenas frutas. Está há 8 anos no mercado, classificada como empresa de pequeno porte, atualmente conta com 4 colaboradores. O Produtor 3, é pessoa física, trabalha com a produção de pequenas frutas. Está há 2 anos no mercado, classificada como empresa de pequeno porte e conta com 4 colaboradores.

A indústria, é pessoa jurídica, trabalha com a produção, compra processamento e venda de pequenas frutas. Está há 26 anos no mercado, classificada como empresa de grande porte. Conta em média com 50 colaboradores. É considerada a principal exportadora de 
pequenos frutos da região. Os entrevistados da indústria foram dois gestores, sendo que um dos entrevistados é o proprietário e a outra entrevistada é a gerente administrativa.

O Varejista, por ser um supermercado trabalha com a compra e venda de produtos. Está há 15 anos no mercado, classificada como empresa de pequeno porte. Conta com 10 colaboradores. $\mathrm{O}$ entrevistado foi o proprietário do supermercado.

O Atacadista possui marca própria e distribui diretamente para redes de supermercados de todo o país. Sua matriz é localizada na cidade de Bom Jesus/RS, conta com aproximadamente 12 colaboradores e é considerada uma empresa de médio porte. 0 entrevistado foi o gerente geral da empresa.

O entrevistado aqui denominado "Insumos" é uma empresa distribuidora de insumos que atende toda a região Nordeste do Estado. Está há 46 anos no mercado, conta com 180 colaboradores. Sua matriz está localizada na cidade de Caxias do Sul e as onze filiais nas cidades de Nova Petrópolis, Farroupilha, Antônio Prado, Caxias do Sul, São Marcos, Bom Jesus, Porto Alegre, Bento Gonçalves e Vacaria. Os entrevistados da empresa foram o gerente de vendas e o consultor de vendas.

\section{ANÁLISE DOS DADOS E DISCUSSÃO DOS RESULTADOS}

Esta seção está estruturada em duas partes: na primeira parte são apresentados os dados e resultados obtidos sobre compartilhamento de conhecimento na cadeia produtiva dos pequenos frutos dos Campos de Cima da Serra, e na segunda parte é realizada uma discussão geral sobre os resultados obtidos com o estudo.

\subsection{Compartilhamento do Conhecimento na Cadeia Produtiva dos Pequenos Frutos}

Nas entrevistas realizadas, todos os entrevistados comentaram que acham importante existir o compartilhamento do conhecimento entre as organizações. De acordo com Anghinoni (2005), onde ele explica que o conhecimento é uma ferramenta para o progresso das organizações. Dessa forma relatam o Produtor 2, o Proprietário e a Gerente Administrativa da Indústria:

“É importante sim, claro que assim, mas a gente sempre tá correndo atrás eu quando tem eventos estou participando né" (Produtor 2).

"Sempre é importante, sem dúvidas. Não podemos ficar fechados. No mundo globalizado como esta hoje, você não pode ficar se cercando de murros, derrubam-se murros e não se constrói muros" (Proprietário da Indústria).

"A troca de informação sempre tem e às vezes tá com algum problema aqui ou lá essa troca de informação sempre existe" (Gerente Administrativa da Indústria).

Percebeu-se através das entrevistas que o conhecimento existente dentro da cadeia produtiva dos pequenos frutos se apresenta na maioria das vezes de forma tácita sendo transmitido através da socialização para os demais elos da cadeia, por meio de conversas, visitas informais e telefonemas. Complementando o que diz Nonaka (1994) e Nonaka, Takeuchi (1995) onde afirmam que a socialização é uma maneira de criar conhecimento que visa à conversão do conhecimento tácito por meio da interação entre indivíduos. Além de Tsai (2002) apontar que, o compartilhamento do conhecimento flui melhor em ambientes 
informais, em ambientes que as relações sociais acontecem naturalmente entre as organizações. Dessa forma relatam o Produtor 2 e a Gerente Administrativa da Indústria:

"A gente até compartilha informação, mas assim informalmente, nada formal, digamos nada de um evento organizado" (Produtor 2).

“O pessoal vem aqui, a gente vai lá, é bem cara a cara mesmo" (Gerente Administrativa da Indústria).

Outro achado por meio do estudo foi o fato que o compartilhamento entre as organizações do mesmo ramo há resistência em compartilhar é citado em diversos momentos e por diversos entrevistados que a concorrência atrapalha bastante na prática de compartilhar conhecimento entre eles. Este achado pode ser explicado melhor por Sordi, Binotto e Ruviaro (2014), para os autores, o nível de competição existente em um determinado grupo de indivíduos influencia no grau de compartilhamento de conhecimentos entre os mesmos. Ou seja, não é tarefa fácil (LEE, 2001). Como observa-se nos relatos dos Produtores 1 e 3 :

\begin{abstract}
“A gente como produtor, troca muita informação com o fornecedor. Por exemplo, com outros produtores de morango aconteceu uma situação ontem para você ter uma ideia, nós estamos construindo aquelas estufas ali que pra nós não é novidade, mas conforme você vai montando vão surgindo dúvidas. Como é que faz? Como fica melhor? O fulano já fez, vamos ver como é que fez. Então ontem mesmo, na parte de irrigação surgiram umas dúvidas fomos visitar três produtores para ver como é que eles fizeram. E só um permitiu receber e permitiu passar a informação para nós" (Produtor 1).

"Tem vezes que a gente troca dependendo do tipo de informação. Mas tem gente que não gosta de passar informação" (Produtor 3).
\end{abstract}

Dentro da cadeia produtiva o fornecedor de insumos é o único que se relaciona apenas com um elo, o produtor. Durante as entrevistas os entrevistados citam que estabelecem um contato acima de vendedor e cliente. É criado um vínculo de amizade entre eles. Segundo Cheng, Yeh e Tu (2008) a confiança é a base para que o compartilhamento do conhecimento aconteça e cada vez se solidifique mais entre as partes, isso faz com que o compartilhamento de conhecimento seja retribuído por ambas às partes. Desta maneira, podem ser observados os relatos do Consultor de Vendas da empresa de Insumos e da Gerente Administrativa da Indústria:

\footnotetext{
“Não é só uma relação comercial, é mais um relacionamento já de confiança que agente fez" (Consultor de Vendas da empresa de Insumos).

"A gente trabalha muito em parceria. Então a gente fideliza o produtor, fideliza o cliente então a gente trabalha bem o cara a cara assim mesmo sabe? É o que a gente mais prioriza" (Gerente Administrativa da Indústria).
}

Foi possível observar que apenas o distribuidor de insumos e os órgãos públicos promovem eventos para estimular o compartilhamento do conhecimento fora da organização. Os órgãos públicos incentivam o compartilhamento do conhecimento de diversas maneiras, como por exemplo, com a criação de feiras e seminários realizados anualmente na região. Já o distribuidor de insumos costuma promover eventos abertos para seus clientes e funcionários participarem, onde são realizadas palestras sobre assuntos atuais da área, assim como oficinas práticas onde é aberta a participação para todos. Conforme relatam o Gerente e o Consultor de Vendas da empresa de Insumos e o Produtor 1:

Perspectivas em Gestão \& Conhecimento, João Pessoa, v. 8, n. 2, p. 82-106, mai./ago. 2018. 
"E a empresa tem também um evento que acontece de dois em dois anos em março, onde a gente reúne todos os produtores da região ali em Caxias em Fazenda Souza e faz um evento bem grande. Os produtores geralmente vão lá, dai interagem nos temos os nossos fornecedores lá. Eles vão lá conhecem sementes. É uma das coisas que a empresa faz que eu acho bem bacana. É um evento aonde toda a clientela da região vai lá" (Gerente da empresa de Insumos).

"A gente sempre tem alinhamento técnico com os fornecedores direto e nos repassamos isso para os produtores tanto que nos tivemos essa semana duas palestras, para você ter uma ideia" (Consultor de Vendas da empresa de Insumos).

“O fornecedor promove. Até teve há poucos dias atrás uma palestra sobre nutrição de plantas, que tinham 5 produtores mas de pequenos frutos só tinha nós. Eles promovem dia de campo, um dia disso, um dia daquilo" (Produtor 1).

Pôde-se perceber que o compartilhamento de conhecimento intraorganizacional é mais presente do que o interorganizacional. Ou seja, os entrevistados quando questionados a respeito do compartilhamento interorganizacional afirmam que, não é com todos os integrantes da cadeia que há liberdade para compartilhar conhecimento. Falam também que por parte de alguns essa prática ainda não é realizada com grande intensidade, principalmente quando se trata de participantes do mesmo nível na cadeia produtiva. Já quando se trata do compartilhamento intraorganizacional a prática é mais aceita. Eles afirmam que quando o compartilhamento é dentro da organização flui naturalmente durante o dia-a-dia através das conversas e telefonemas informais. Este achado converge com o estudo de Anghinoni (2005), o autor entende que as empresas do agronegócio têm problemas para identificar e guardar os ativos do conhecimento. A identificação de quem são esses ativos é fundamental para o crescimento e desenvolvimento dos negócios não só do ramo do agronegócio como para todos os ramos. Essa identificação poderá se transformar na principal fonte de vantagem competitiva, como explica o Gerente e o Consultor de Vendas da empresa de Insumos e o Proprietário da Indústria:

"Geralmente é feita a parte de treinamento, quem nos dá muito treinamento também, são as nossas bandeiras né, que são nossos fornecedores. Por exemplo, assim, essa época do ano a gente já fez quatro ou cinco treinamentos. Eles chamam de alinhamento de venda que seria quando nós alinhamos com o fornecedor cada produto dele, quais as estratégias nossas" (Gerente da empresa de Insumos).

"Nós temos encontro na matriz que é em Caxias, aonde nós temos interação, integração e troca de conhecimentos entre todos os funcionários. Sempre tem vários encontros por ano" (Consultor de Vendas da empresa de Insumos).

"Treinamentos a gente busca primeiro via Internet. A gente faz experimento na própria empresa se não juntamente com órgãos do governo" (Proprietário da Indústria).

Outrossim, os órgãos públicos são grandes apoiadores e estimuladores do compartilhamento do conhecimento, conforme relata o Produtor 2, a Gerente Administrativa e o Proprietário da Indústria: 
"São mais órgãos públicos que trazem, que nem a Embrapa. Ou alguma empresa de insumo que dai quer apresentar alguma coisa né. São mais esses órgãos do governo" (Gerente Administrativa da Indústria).

“A Embrapa, a gente abre espaço para vim os pesquisadores aqui. Já faz um ano que dois pesquisadores estão vindos para fazer uma pesquisa sobre essa mosca, esse inseto novo que se infiltrou então essa pesquisa que eles estão fazendo é uma parceria com a Embrapa e nos seremos os primeiros, a saber, qual o produto para combatê-la" (Proprietário da Indústria).

"Geralmente quem toma iniciativa é o setor público como houve agora os seminários e tal. Das empresas mesmo é difícil" (Produtor 2).

Mesmo com os eventos promovidos pelos órgãos públicos como meio de incentivo ao compartilhamento do conhecimento a Indústria e o Atacadista não demostra tanto interesse em participar por esse motivo, e sim participam visando a divulgação da marca ou da empresa. Conforme podemos observar no relato da Gerente Administrativa da Indústria:

\begin{abstract}
“[...] ela é mais importante para mostrar que a empresa está na comunidade, que a empresa existe né. Para as pessoas conhecerem não é que ela traga lucro de vendas, por exemplo, não é isso. Mas em contrapartida ela te traz um beneficio que é a sociedade saber que a empresa existe que esta aqui e esta empregando pessoas né. Que se produzem esses produtos na cidade. Então é mais uma questão de divulgar mesmo que a empresa existe e para divulgar mais o consumo dos pequenos frutos mesmo né?" (Gerente Administrativa da Indústria).
\end{abstract}

Observa-se que o compartilhamento de conhecimento dentro da cadeia produtiva de pequenos frutos não envolve o consumidor. Todos os consumidores entrevistados citam que não estabelecem compartilhamento com nenhum elo da cadeia. Foi abordada a existência de um evento realizado anualmente na cidade, que eles podem visitar e participar de algumas oficinas. Porém não consideram como meio influenciador de compartilhamento. Dessa maneira relatam os três consumidores entrevistados:

"O consumidor não tem né vinculo nenhum com o produtor" (Consumidor 1).

"Não tem contato, só compro o produto no mercado" (Consumidor 2).

"Não, a nossa empresa compra direto do representante comercial" (Consumidor 3).

Por fim, apesar de todos notarem a importância de compartilhar conhecimento, essa prática ainda não é realizada por todos os integrantes da cadeia. Nota-se certa resistência principalmente quando o compartilhamento é entre empresas concorrentes no mercado. A promoção de técnicas e eventos que favoreçam o compartilhamento do conhecimento é escassa.

\title{
5.2 Discussão dos Resultados
}

Ao analisar os resultados obtidos com a pesquisa foi possível perceber que todos os entrevistados percebem a importância de compartilhar conhecimento tanto em nível intraorganizacional como interorganizacional. Desde modo, este achado converge com Anghinoni (2005), ou seja, o autor entende que diante do mercado de hoje, com 
transformações constantes e rápidas, o conhecimento torna-se fator importante no cenário do agronegócio. Desta maneira, as empresas do agronegócio precisam tratar o conhecimento como base primordial para planejar e agir.

Ainda assim, foi possível perceber que o compartilhamento do conhecimento não é aplicado por todos os membros da cadeia produtiva dos pequenos frutos. Mesmo notando que a prática é importante os entrevistados não tomam nenhuma atitude para estimular a ação de compartilhamento. O estímulo para essa prática vem na maioria das vezes por Órgãos Públicos. Outro participante da cadeia produtiva que promove esse tipo de eventos é o distribuidor de insumos envolvendo seus clientes (produtores).

Os três produtores que foram entrevistados, relataram que entre eles há resistência em compartilhar conhecimento. Pois a maioria vê o compartilhamento como um fator que vai ser prejudicial em relação à concorrência. Já com os demais elos, o compartilhamento ocorre de maneira mais tranquila, sem barreiras. Dyer e Nobeoka (2000) argumentam este fato dizendo que a organização deve fazer parte ativamente da cadeia a qual faz parte se tornando um elemento participante no compartilhamento de conhecimento.

A interação entre eles ocorre na sua maioria através da socialização, por meio de conversas informais. Nada fica documentado. Temos uma exceção que é o distribuidor de insumos o que procura documentar o contato direto com o produtor, conforme cita o Gerente da empresa de Insumos:

"Nós temos o chamado laudo visita técnica dentro do próprio tablet do consultor ele mensura, por exemplo, ele fez dez visitas no dia então lá ele vai contar: eu fiz a visita lá, abordamos tais assuntos" (Gerente da empresa de Insumos).

Também foi abordada na entrevista realizada com a Gerente Administrativa da Indústria a existência de treinamentos proporcionado por eles, disponíveis para os funcionários, conforme relato:

“[...] nós temos certificado dos treinamentos, tem o certificado de cada funcionário a gente faz uma reunião com todos quando é repassada alguma informação sempre tem um certificado" (Gerente Administrativa da Indústria).

Em contrapartida o Produtor 1, em sua entrevista diz que foi realizado uma tentativa de conversão do conhecimento interorganizacional tácito para explícito, porém não obtiveram sucesso. Houve resistência dos colaboradores, os quais não aceitaram a interferência de outras pessoas na relação estabelecida entre funcionários. Conforme palavras do mesmo:

"[...] a gente até tentou, assim, fazer uma parte de como é que eu vou te explicar, o fulano faz assim e o ciclano faz assim. Vamos unir essas duas informações, e passar para os demais, mas como muitas pessoas tem resistência a mudanças, então eu faço assim eu me sinto melhor assim. Se for entre eles, eles conseguem se integrar melhor na conversa entre eles, mas agora se partir da empresa a mudança eles tem resistência" (Produtor $1)$.

O conhecimento é encontrado na cadeia produtiva dos pequenos frutos, em sua maioria, na forma tácita. Ou seja, muita pouca coisa fica documentada. No Quadro 2 pode-se observar a forma como o conhecimento atinge os entrevistados. O conhecimento tácito é apontado pelos entrevistados como conversas informais, telefonemas e visitas informais. Já o conhecimento explícito é utilizado pelo distribuidor de insumos e pela indústria, na forma de cursos, seminários, e-mails, feiras, manuais, relatórios, e dias de campo. Assim como, eventos 
promovidos pela própria empresa, como é o caso dos insumos, onde tudo que acontece no evento é devidamente documentado.

\begin{tabular}{|c|c|c|c|c|c|c|c|c|c|c|}
\hline \multicolumn{11}{|c|}{ Quadro 2 - Mecanismos de Compartilhamento } \\
\hline \multirow[b]{2}{*}{$\begin{array}{c}\text { Membros da } \\
\text { Cadeia } \\
\text { Produtiva }\end{array}$} & \multicolumn{3}{|c|}{ CONHECIMENTO TÁCITO } & \multicolumn{7}{|c|}{ CONHECIMENTO EXPLÍCITO } \\
\hline & 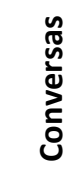 & 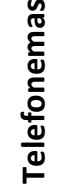 & $\frac{\stackrel{n}{ \pm}}{\stackrel{n}{n}}$ & 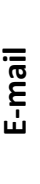 & $\begin{array}{l}\frac{n}{\pi} \\
\frac{n}{2} \\
\frac{1}{\pi} \\
\sum\end{array}$ & 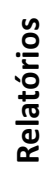 & 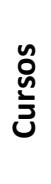 & 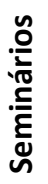 & 氜 & 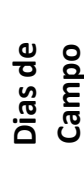 \\
\hline Insumos & $\mathrm{X}$ & $\mathrm{X}$ & $x$ & $\mathrm{x}$ & $\mathrm{X}$ & $\mathrm{X}$ & $\mathrm{X}$ & $\mathrm{X}$ & $\mathrm{X}$ & $\mathrm{X}$ \\
\hline Produtor 1 & $\mathrm{X}$ & $\mathrm{X}$ & $x$ & $\mathrm{x}$ & & & $\mathrm{X}$ & $\mathrm{X}$ & $\mathrm{X}$ & \\
\hline Produtor 2 & $\mathrm{X}$ & & & & & & & $\mathrm{X}$ & $\mathrm{X}$ & \\
\hline Produtor 3 & $\mathrm{X}$ & & & & & & & & $\mathrm{X}$ & \\
\hline Indústria & $\mathrm{X}$ & $\mathrm{X}$ & $X$ & $\mathrm{x}$ & & & $\mathrm{X}$ & $\mathrm{X}$ & $\mathrm{X}$ & $\mathrm{X}$ \\
\hline Atacado & $\mathrm{X}$ & $\mathrm{X}$ & $x$ & $x$ & & & & & $\mathrm{X}$ & \\
\hline Varejista & $\mathrm{X}$ & $\mathrm{X}$ & & & & & & & & \\
\hline Consumidor 1 & $x$ & & $x$ & & & & & & $\mathrm{X}$ & \\
\hline Consumidor 2 & $\mathrm{X}$ & & $x$ & & & & & & $X$ & \\
\hline Consumidor 3 & $x$ & $\mathrm{X}$ & $X$ & $X$ & & & & & & \\
\hline
\end{tabular}

Fonte: Elaborado pelos Autores (2016).

Como pode ser observado, o Quadro 2 apresenta os tipos de conhecimento e quais os mecanismos utilizados para compartilha-lo, assim sendo, percebe-se que o distribuidor de Insumos compartilha conhecimento tanto de forma tácita por meio de conversas, telefonemas e visitas quanto explícita através de e-mails, relatórios, cursos, seminários, feiras e dias de campo. Já nos produtores pode-se observar divergência na forma como compartilham. 0 Produtor 1 consegue expandir o leque de mecanismos comparado com os demais produtores. Os recursos de compartilhamento comum a todos os produtores são apenas as conversas e as feiras. A Indústria apresenta conhecimento tácito através de conversas, telefonemas e visitas e o conhecimento explicito aparece na forma de cursos, seminários, feiras e dias de campo. 0 comércio Atacadista atinge o conhecimento explicito somente através de feiras, já o tácito por meio de telefonemas, visitas e conversas. O comércio varejista não utiliza nenhum mecanismo para compartilhar conhecimento explicito, já o conhecimento tácito é compartilhado por meio de conversas e telefonemas. Os mecanismos utilizados pelos consumidores 1 e 2 são os mesmos, pelo fato de serem pessoas físicas. Já o Consumidor 3 , pessoa jurídica, utiliza apenas o e-mail como auxiliador no compartilhamento de conhecimento explícito.

Através do estudo foi possível notar algumas alterações na cadeia produtiva proposta por de Zylberstajn (1994). Foram constatadas outras relações existentes entre os membros da cadeia produtiva dos pequenos frutos além das já existentes. Na entrevista com a Gerente Administrativa da Indústria descobriu-se o vínculo do consumidor diretamente com a indústria, assim como na entrevista com o Consumidor 3 , a descoberta foi em relação à existência de vinculo direto entre o consumidor e o produtor.

Pode-se perceber na Figura 3 que o fornecedor de insumos compartilha conhecimento tanto tácito quanto explícito, mas este compartilhamento somente acontece com os 
produtores. Já os produtores compartilham conhecimentos com a indústria e com o comércio, porém somente de forma tácita. Todavia o compartilhamento entre indústria e produtor se manifesta das duas maneiras. O consumidor tem relação com o comércio varejista, com a indústria e com os produtores, no entanto compartilhando apenas conhecimento tácito.

Figura 3 - Conhecimento na Cadeia Produtiva dos Pequenos Frutos

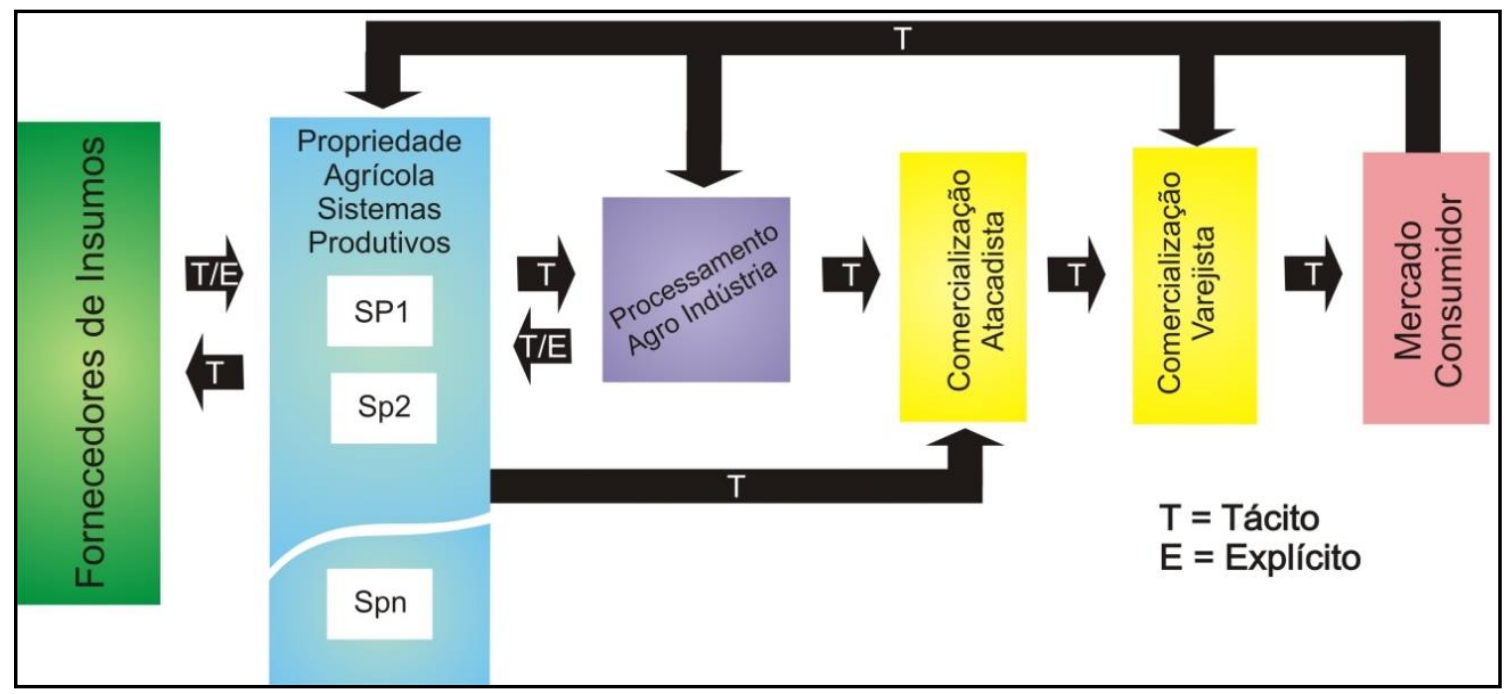

Fonte: Adaptado pelos Autores (2016).

Portanto, na cadeia produtiva dos pequenos frutos existe a percepção da importância do compartilhamento do conhecimento por parte de seus integrantes. Todavia há resistências em relação a quem compartilhar e em criar ambientes propícios ou estimuladores para o compartilhamento. Outro fator importante a se destacar é que a maioria do conhecimento que percorre a cadeia encontra-se na forma tácita, e o fato de não haver a transformação do que é tácito para explicito gera perda de muito conhecimento relevante, que poderia ser utilizado por outros membros da cadeia ou até pelo próprio gerador do conhecimento em longo prazo.

\section{CONSIDERAÇÕES FINAIS}

Esta pesquisa teve como objetivo: analisar como acontece o compartilhamento do conhecimento dentro da cadeia produtiva dos pequenos frutos na região dos Campos de Cima da Serra. Deste modo, com os resultados obtidos foi possível constatar que o compartilhamento do conhecimento hoje já é visto como fator diferencial para as organizações, e que está sendo reconhecido como um dos principais ativos geradores de valor. Percebe-se também que o tipo de conhecimento predominante na cadeia produtiva dos pequenos frutos é o conhecimento tácito. O que faz com que muitas informações sejam perdidas, esquecidas, ou não recebam o seu devido valor.

Foi possível observar no estudo que todos os membros da cadeia, entendem a importância do compartilhamento do conhecimento. Porém, foi percebida certa resistência por parte de alguns entrevistados referente ao compartilhamento de conhecimento com pessoas ou empresas concorrentes (produtor com produtor). Observou-se também que as empresas de maior porte, como a indústria e a distribuidora de insumos são os principais pontos da cadeia onde o compartilhamento é estimulado e encontra-se em suas duas formas, tácito e explícito. 
Outro fator importante é que o compartilhamento do conhecimento nessa cadeia, geralmente parte de iniciativas de órgãos públicos. Os quais promovem feiras e seminários na região, abertos ao público, porém não são todos que veem relevância em participar de tais eventos. Além desses eventos promovidos por esses órgãos também são realizadas pesquisas, onde alguns membros da cadeia abrem espaço para pesquisadores visitarem suas propriedades, o que posteriormente é gerado artigos ou reportagens distribuídas para os demais participantes da cadeia produtiva.

Deste modo, foi possível concluir que o compartilhamento do conhecimento na cadeia produtiva dos pequenos frutos existe e já é reconhecido como fator importante para todos os elos da cadeia. Contudo, mesmo reconhecendo essa importância o compartilhamento não é praticado por todos. Muitos apenas recebem o conhecimento e não procuram meios de promover o compartilhamento.

Ainda assim, é importante ressaltar que houve algumas dificuldades no desenvolvimento do estudo, considerando o fato de que os entrevistados tinham perfis completamente diferentes, houveram resistências na abordagem para a realização da entrevista, principalmente por parte de produtores e consumidores. Também foi encontrada dificuldade em relação à avaliação do questionário pelos especialistas, onde os prazos não foram cumpridos, atrasando o cronograma da pesquisa estipulado.

Por fim, recomenda-se que esse estudo tenha continuidade, onde novos trabalhos poderiam ser realizados, estabelecendo os perfis dos componentes da cadeia produtiva dos pequenos frutos, assim como também seria de grande valia fazer o mesmo estudo, em outra região do estado ou em outra localidade do país. Além de poder ser proposto um framework de compartilhamento do conhecimento para esta cadeia, o qual posteriormente poderá ser testado em outras cadeias produtivas.

\section{REFERÊNCIAS}

ALARCAN, J. S. M. A. et al. Sistema Produtivo de Mertilo. Anais 10 seminário brasileiro sobre Pequenas Frutas. 2003. Embrapa uva e vinho.

ANGELONI, M. T. (ORG.). Organizações do Conhecimento: Infraestrutura, Pessoas e tecnologias. São Paulo: Saraiva, 2002. V.1.2015 p.

ANGHINONI, E. M. L. A importância estratégica do conhecimento nos diferentes níveis organizacionais em empresas do agronegócio de Rondonópolis. Faculdade do Sul de Mato Grosso - FACSUL Curso de Administração com habilitação em Comércio. Rondonópolis - MT. 2005.

ANTUNES, J; et al. Sistemas de Produção. Porto Alegre: Bookman, 2007.

BATALHA, M. (coord) Gestão agroindustrial. São Paulo: atlas, 1997.

BAUER, M. W.; GASKELL, G. (org.). Pesquisa qualitativa com texto, imagem e som: um manual prático. Petrópolis: Vozes, 2002. 448 p.

BINOTTO, E.; NAKAYAMA, M. K. Do Modelo De Nonaka E Takeuchi A Um Novo Método De Análise Da Criação De Conhecimento Para A Realidade Específica Do Agronegócio. 30 encontro da ANPAD. Salvador / BA. Setembro de 2006. 
BINOTTO, E; SIQUEIRA, S. E; NAKAYAMA, M. K. Criação de conhecimento no agronegócio: estudo de casos. Revista de Administração da Universidade Federal de Santa Maria, v. 2, n. 3, set./dez. 2009.

BIZOTTO, B. L. S. Caracterização da Cadeia Produtiva de Pequenas Frutas nos Campos de Cima da Serra sob a ótica da produção e comercialização. Programa de Pós-Graduação em Administração - PPGA. Curso de Mestrado Universidade de Caxias do Sul. Caxias do Sul 2011

BOGDAN, R.; BILKEN, S. (1994). Investigação qualitativa em educação. Editora: Porto.

BRITO, L. M. P., GALVÃO, A. P., OLIVEIRA, P. W. S. de. Gestão do conhecimento em Empresa Internacional de Energia. Rio de Janeiro: EnANPAD. 2012.

CASTRO, A. M. G; et al. La dimensión "Futuro" en la construcción de la sostenibilidad institucional. ISNAR, Proyecto Nuevo Paradigma, San Jose, Costa Rica, 2001 (98p.).

CEPEA ESALQ/USP. Centro De Estudos Avançados Em Economia Aplicada. PIB Agro CEPEAUSP/CNA. Disponível em: <http://cepea.esalq.usp.br/pib/>. Acesso em: 01 jun. 2016.

CHENG, J.-H.; YEH, C.-H.; TU, C.-W. Trust and knowledge sharing in green supply chains. Supply Chain Management: An International Journal, v. 13, n. 4, p. 283-295, 2008.

CHRISTENSEN, P.H. Knowledge sharing: moving away from the obsession with best practices. Journal of Knowledge Management, v. 11, n. 1, p. 36-47, 2007.Companies Create the Dynamics of Inovation. Oxford University Press, Nova York, NY, 1995.

COREDES. Perfil Socioeconômico - Campos de Cima da Serra. Disponível em: $<$ http://www.fee.rs.gov.br/perfilsocioeconomico/coredes/detalhe/?corede=Campos + de+Cima + da+Serra> Acesso em 27/11/2015 às 15h30min.

DANTAS, A. KERTSNTZKY, J: PROCHNIK V. Firma, Indústria e Mercados: more than a new name for logistics. The international Journal of Logistics Management. V.8, 1997.

DAVENPORT E PRUSAK, LAURENCE. Conhecimento Empresarial - Como as organizações gerenciam o seu capital intelectual. Rio de Janeiro: Campus, 1999.

DAVIS, J. H; GOLDBERG, R. A. A concept of agribusiness. Boston: Harvard University. 1957. 135 p.

DUBÉ, L.; PARÉ, G. Rigor in information systems positivist case research: current practices, trends, and recommendations. MIS Quarterly, v. 27, n. 4, p. 597-635, 2003.

DURSKI, Gislaine Regina. Avaliação de Desempenho em Cadeias de Suprimentos. Revista FAE, Curitiba, V.6, n. 1, p.29 janeiro a abril 2003.

DYER, J.H.; NOBEOKA, K. Creating and managing a high performance Knowledge-sharing network: the Toyota case. Strategic Management Journal, v. 21, n.3, p. 345-367, 2000. 
EMBRAPA. VIII Seminário brasileiro de pequenas frutas. Disponível em: $<$ https://www.embrapa.br/busca-de-eventos/-/evento/152779/viii-seminario-brasileiro-sobrepequenas-frutas $>$. Acesso em 01 dez. 2015.

FAORO, R. R.; OLIVEIRA, M. Compartilhamento do Conhecimento Intraorganizacional E Interorganizacional: Empresas do Setor de Fruticultura. Perspectivas em Gestão \& Conhecimento, João Pessoa, v. 4, n. 1, p. 98-118, jan./jun. 2014.

FERNANDES, B. M.Cercas do latifúndio: Agronegócio é o novo nome fantasia da agricultura capitalista, que tenta modernizar sua imagem, mas reforça a exploração e concentração de terra. [20 de mai de 2005]. Disponível em <www.planetaportoalegre.net> Acesso em $10 / 10 / 2015$ às 14 horas.

FONSECA, J. J. S. Metodologia da pesquisa científica. Fortaleza: UEC, 2002. Apostila.

GIL, A. C. Métodos e Técnicas de Pesquisa Social. São Paulo: Atlas, 2002.

GIL, A.C. Métodos e Técnicas de pesquisa social. 5. Ed. São Paulo: Atlas, 1999.

GLOBO, Bom Dia Rio Grande. RS está entre os estados mais competitivos para agronegócio: reportagem. [03 de dez de 2014]. Disponível em: <http://g1.globo.com/rs/rio-grande-dosul/bom-dia-rio-grande/videos/t/edicoes/v/rs-esta-entre-os-estados-mais-competitivos-paraagronegocio/3805815> Acesso em 22/08/2015 às $21 \mathrm{hrs}$.

GLOBO, G1. Agronegócio tem participação recorde de $\mathbf{5 1 , 5 \%}$ nas exportações brasileiras em maio. [Jan de 2015].Disponível em: <http://g1.globo.com/economia/noticia/2015/01/balancacomercial-registra-em-2014-primeiro-deficit-desde-2000.html> Acesso em: 08/06/2015 às $15 \mathrm{~h} 42 \mathrm{~min}$.

GOLDENBERG, M. (1999) A arte de pesquisar: como fazer pesquisa qualitativa em Ciências Sociais. Rio de Janeiro: Record.

GROTTO, D. O compartilhamento do conhecimento nas organizações. In: ANGELONI, Maria Terezinha (Coord.). Organizações do conhecimento: infraestrutura, pessoas e tecnologias. São Paulo: Saraiva, 2003.

JAMANDRE, W. E. Agribusiness: A Perspective. Department of Agribusiness Management Central Luzon State University Science City of Muñoz, Nueva Ecija. Disponível em: www.openuni-clsu.edu.ph/openfiles/.../lesson1.doc. Acesso em 03 nov. 2015.

JARVENPAA, S. L.; STAPLES, D. S. Exploring perceptions of organizational ownership of information and expertise. Journal of Management Information Systems, v. 18, n. 1, p. 151183, 2001.

LEE, J.-N. The impact of knowledge sharing, organizational capability and partnership quality on IS outsourcing success. Information \& Management, v. 38, p. 323-335, 2001.

LEV, B. A matemática da nova economia. Revista HSM Management, São Paulo, maio-jun, 2000. 
LI, W. Virtual knowledge sharing in a cross-cultural contexto. Journal of Knowledge Management, v. 14, n. 1, p. 38-50, 2010.

LOURENÇO, C; LIMA, B. Evolução do agronegócio brasileiro, desafios e perspectivas. Observatório de Economia Latino-americana. Número 118, 2009. Disponível em: $<$ http://www.eumed.net/cursecon/ecolat/br/>. Acesso em 25 ago. 2015.

MAPA, Ministério da Agricultura, Pecuária e Abastecimento. O Agronegócio no Brasil. Disponível em: <http://www.ecoagro.agr.br/agronegocio-brasil >. Acesso em: 21 ago. 2015.

MINAYO, M. C. de S. (Org.). Pesquisa social: Teoria, método e criatividade. Petrópolis: Vozes, 2001. 80 p.

MONTIGAUD, J.C.L. Analyse dês filières agro-alimentaires: méthodes et premiers résultats. Economies et Sociétés, serie AG, n.21,1992.

MONTOYA, M. A. O agronegócio no Mercosul: dimensão econômica, desenvolvimento industrial e interdependência estrutural na Argentina, Brasil, Chile e Uruguai. Rev. Bras. Econ., Rio de Janeiro, v. 56, n. 4, p. 605-660, Oct. 2002.

MORVAN, Y. Filière de production. In: MORVAN, Y. Fondements d'Economie Industrielle. 2 eme ed. Paris, Econômica, p. 243-275, 1991.

NAN, N. A principal-agent model for incentive design in knowledge sharing. Journal of Knowledge Management, v. 12, n. 3, p. 101-113, 2008.

NONAKA, I.; VON KROGH, G. Tacit Knowledge and Knowledge Conversion: Controversy and Advancement in Organizational Knowledge Creation Theory. Organization Science, v. 20, n. 3, p. 635-652, 2009.

NONAKA, I; TAKEUCHI, H. Criação de Conhecimento na Empresa. 12a. Edição. Rio de Janeiro: Campus, 1997.

NONAKA, I; TAKEUCHI, H. Criação do Conhecimento na empresa: Como as empresas japonesas geram a dinâmica da informação. Rio de Janeiro: Campus, 1997.

OLIVEIRA, B. Confira dados que demonstram a importância do agronegócio no Brasil. Portal Avante Brasil. [05 de mar de 2015]. Disponível em: $<$ http://portal.avantebrasil.com.br/blog/agronegocios/confira-dados-que-demonstram-aimportancia-do-agronegocio-no-brasil> Acesso em: 08 jun. 2015.

OLIVEIRA, R.R.; SAUER, A.B.S. Gestão compartilhamento de conhecimento em uma empresa familiar: um estudo à luz da investigação apreciativa. Perspectivas em Gestão \& Conhecimento, João Pessoa, v. 6, n. 1, p. 175-199, jan./jun. 2016

ORMOND, J. G. P; et al. Agricultura orgânica: quando o passado é futuro. BNDES Setorial, Rio de Janeiro, n. 15, p. 3-34, 2002. 
OTOBELLI, D. O crescimento constante e a boa remuneração incentivam o cultivo das 'berries', que estão em plena colheita nos Campos de Cima da Serra. AVINDIMA. 2013. Disponível em: $<$ http://www.avindima.com.br/?p=5849> Acesso em: 15 setembro 2015.

PAGOT, E; HOFFMANN, A. Pequenas frutas. In: Seminário Brasileiro Sobre Pequenas Frutas, 1., 2003, Vacaria, RS. Anais. Bento Gonçalves, RS: Embrapa Uva e Vinho, 2003, p.7-15. (Documentos, 37). Disponível em: <http://biblioteca.versila.com/9478679>. Acesso em: $25 / 10 / 15$ às $23 \mathrm{~h} 54 \mathrm{~min}$.

PAGOT, Eduardo. Demanda e Contribuições para inovação em pequenas frutas. IV Seminário Brasileiro Sobre Pequenas Frutas - Vacaria, RS, Julho, 2007.

POLTRONIERI, E. Alternativas para o mercado interno de pequenas frutas. In: Seminário Brasileiro Sobre Pequenas Frutas, 1., 2003, Vacaria, RS. Anais. Bento Gonçalves, RS: Embrapa Uva e Vinho, 2003, p.37-40. (Documentos, 37)

RIBEIRO, E. A. A perspectiva da entrevista na investigação qualitativa. Evidência: olhares e pesquisa em saberes educacionais. Araxá/MG, n. 04, maio de 2008.

RUFINO, J. L.S. Origens e conceitos do agronegócio. Informe Agropecuário, Belo horizonte: Epamig, v.20, n. 199, Jul./Ago. 1999.

STEWART, T. A. Capital Intelectual: A Nova Vantagem Competitiva das Empresas. Rio de Janeiro: Ed. Campus, 1998.

SORDI, V. F. BINOTTO, E. RUVIARO, C. F. A Cooperação e o Compartilhamento de Conhecimentos em uma Cooperativa de Crédito. Perspectivas em Gestão \& Conhecimento, João Pessoa, v. 4, n. 1, p. 119-134, jan./jun. 2014.

TONET, H. C.; PAZ, M. G. T. Um modelo para o compartilhamento de conhecimento no trabalho. Revista de Administração Contemporânea. V. 10, n. 2, 2006.

TORESAN, Luiz. Marketing e agribusiness. Disponível em Site: www.ufsc.com. Acesso no dia 26/04/2007.

TSAI, W. Social structure of "coopetition" within a multiunit organization. Coordination, competition, and intraorganizational knowlege sharing. Organization Science, v. 13, n. 2, p. 179-190, 2002.

VERGARA, S. C. Projetos e relatórios de pesquisa em administração. 8. ed. São Paulo: Atlas, 2007. 96p.

VIEIRA, W. C. (Ed.). Agricultura na virada do milênio: velhos e noves desafios. Viçosa, 2000. p. 93-116. 
WANG, S.; NOE, R. A. Knowledge sharing: A review and directions for future research. Human Resource Management Review, v. 20, n. 2, 2010.

YIN, R. K. Estudo de caso: planejamento e método. 2. ed. Porto Alegre: Bookman, 2001.

ZYLBERSZTAJN, D. Organização de cooperativas: desafios e tendências. Revista de Administração, São Paulo, v.29, n.3, p.23-32, jul./set. 1994.

ZYLBERSZTAJN, D. Conceitos Gerais, Evolução e Apresentação do Sistema Agroindustrial. In: ZYLBERSZTAJN, D.; NEVES, M. F. Economia e gestão dos negócios agroalimentares: indústria de alimentos, indústria de insumos, produção agropecuária, distribuição. São Paulo: Pioneira, 2000, p. 1-21.

Artigo recebido em 02/04/2017 e aceito para publicação em 30/05/2018 